\title{
Angiogenesis and expression of vascular endothelial growth factor and endostatin protein in myocardial infarction rat model
}

\author{
Chenglong Zheng,,2, Panchu Yang3, Lu Zhang', Zhiyong Wang', Kun Chen'1, Yue Lan4, \\ Xing Zhai ${ }^{1}$, Kun Huang' and Shuwen Guo'
}

\begin{abstract}
${ }^{1}$ Beijing University of Chinese Medicine, 11 Bei San Huan Dong Lu, ChaoYang District, Beijing 100029, P. R. China; ${ }^{2}$ Beijing Drum Tower Hospital of Traditional Chinese Medicine, 13 Dou Fu Chi Hutong, Dongcheng District, Beijing 10009, P. R. China; ${ }^{3}$ Comprehensive Section, Liangxiang Hospital, Afflicated Hospital of Yanjing Medical College of Capital University of Medical Science, No. 45, Gongchen North Street, Liangxiang Country, Fangshan District, Beijing 102401, China; ${ }^{4}$ Department of Traditional Chinese Medicine of Fuwai Hospital, CAMS and PUMC, 137 Bei Li Shi Lu, Xicheng District, Beijing 10009, P. R. China.
\end{abstract}

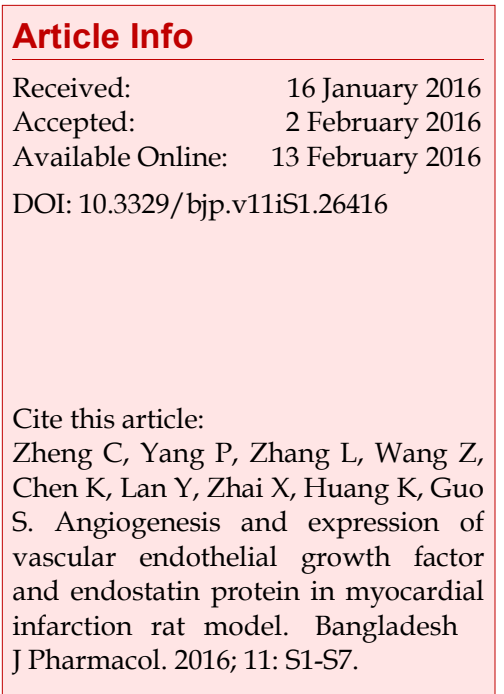

\begin{abstract}
The aim of this study was the effects of supplementing qi and herbs that promote neovascularization on angiogenesis and expressions of vascular endothelial growth factor and endostatin protein in experimentally induced acute myocardial infarction in rats. Left anterior descending coronary artery was ligated to establish the acute myocardial infarction model. Microvascular vascular count and expressions of vascular endothelial growth factor and endostatin protein were detected and indexes were detected at 7 th, 14th and 28th day. The results showed large doses of qi herbs combined with small doses of activating herbs are superior to other groups in promoting the angiogenesis, increasing vascular endothelial growth factor protein expressions and reducing endostatin protein expressions. It also showed that there was a doseresponse effect of supplementing qi and activating blood circulation herbs promoting angiogenesis. The mechanism of supplementing qi and activating blood circulation herbs and combination of both promoted angiogenesis due to possibly to increased vascular endothelial growth factor protein expressions and reduced endostatin protein expressions.
\end{abstract}

\section{Introduction}

Myocardial angiogenesis is one of the important mechanisms of myocardial protection. The state of blood vessels is closely related to the presence of rapid generation in areas of vascular infarction. This approach is to promote new vessel formation and enhance or establish collateral circulation in infarcts. Inadequate coronary blood flow and perfusion may lead to myocardial infarction (Lee et al., 2012; Jazi et al., 2012)

This paper was presented in the 3rd International Conference on Biomedicine and Pharmaceutics in Zhuhai, China, on December 11-13, 2015.
In recent years, coronary artery bypass graft and percutaneous transluminal coronary angioplasty had helped to increase blood perfusion of myocardial infarction (Halkos et al., 2011). These invasive approaches however, are found to be less effective in treating dispersed fine or deep lesions in coronary arteries. Therefore, therapeutic angiogenesis has become a focus of research to treat vasomotor factor that could regulate and balance angiogenesis and neovascularization in the infarct (Koyama, 2011), providing possibly hope for the treatment of acute myocardial infarction through therapeutic angiogenesis.

At present, vascular endothelial growth factor and 
bFGF are cited to be important proteins promoting angiogenesis. However, angiogenesis is a complicated process (Jung et al., 2010). Therefore, based on previous studies (Guo et al., 2005; Guo et al., 2005; Guo et al., 2012), the present study was undertaken to evaluate the importance of angiogenesis and expression of vascular endothelial growth factor and endostatin proteins in experimentally induced myocardial infarction in rats through Traditional Chinese Medicine therapy using qi and herbs that promote coronary circulation.

\section{Materials and Methods}

\section{Animals}

Male Sprague-Dawley rats were purchased from Beijing Vital River Lab Animal Technology Co., Ltd. (Certificate No. SCXK 2014-0001). Initially weighing 230 $\pm 20 \mathrm{~g}$ (aged 10 weeks) were used in the study. All rats were housed under constant conditions at the temperature of $23 \pm 1^{\circ} \mathrm{C}$, humidity of $40 \pm 5 \%$, and on a 12 hours light/dark-cycle. Rats had free access to a standard diet and to drink water.

\section{Drugs and reagents}

Supplementing qi herbs include astragalus and ginseng, and activating blood circulation herbs include Chuanxiong, Panax and Pueraria (provided by Pharmaceutical Factory of Beijing University of Chinese Medicine). The positive control drugs were: Tongxinluo (TXL) capsule, Yiling Pharmaceutical Company (approval number: Z19980015, $0.26 \mathrm{~g} /$ pill). Drugs for model were: 1\% furosemide (Tianjin Jin Yao Amino Acid Co., Ltd., production batch number: 0705093); $2 \%$ lidocaine injection (Beijing Yongkang Pharmaceutical Co., Ltd., production batch number: 07,040,204); injection of penicillin sodium (North China Pharmaceutical Co., Ltd., production batch number: Y0703113); 1\% pentobarbital sodium injection (Shanghai Chemical Pharmaceutical Co., Ltd., production batch number: F20030816). Main reagent were: CD34 antibody (Santa Cruz); vascular endothelial growth factor antibody (Santa Cruz); endostatin antibodies (Santa Cruz).

\section{Experimental myocardial infarction}

\section{Model establishment}

Myocardial infarction was produced in rats by ligation of the left anterior descending coronary artery for 4 weeks. The surgical procedure was performed according to a previous study with minor modifications (Guo et al., 2012; Stanton et al., 2000). Briefly, the rats were anesthetized with urethane $(1.2 \mathrm{~g} / \mathrm{kg}$, ip), and then underwent a left thoracotomy. The incised area was extended by forceps and the pericardium was opened. After tracheal intubation, the rats were ventilated by a respirator with room air at a tidal volume of 25 $\mathrm{mL} / \mathrm{min}$ and a respiratory rate of 70 cycles $/ \mathrm{min}$. The heart was exteriorized, and ligated at the proximal left anterior descending coronary artery 2-3 $\mathrm{mm}$ from its origin between the pulmonary artery tonus and the left atrium with a 4-0 proline suture. The heart was returned to its normal position, and the thorax was closed. Sham operated rats underwent the identical surgical procedure as described above except that the suture was not tightened around the coronary artery.

Experimental groups

The rats with acute myocardial infarction were randomly divided into 6 groups, including model group (control), activating blood circulation herbs group (blood group), supplementing qi herbs group (qi group), supplementing qi herbs/activating blood circulation herbs 1:2 group (1:2 Group), supplementing qi herbs/ activating blood circulation herbs 2:1 group (2:1 Group) and Tongxinluo capsule group (TXL group), and a sham operation group (sham group) set up as negative control group. Electrocardiogram inspection was done after 5 days modeling, the severity of myocardial infarction was judged by the total of $\mathrm{Q}$ wave quantity of $\mathrm{I}$, avL and V1-V6, and different degree of infarction too much or too light rats were removed to guarantee that there were 11 rats in the sham operation group and all the model group at 7 th, 14 th and 28 th day.

\section{Drug quantity}

Sham group: No medicine intervention the same volume of sterile distilled water were fed daily; Model group: No medicine intervention, the same volume of sterile distilled water were fed daily; TXL group: Heart pill of TXL, $30 \mathrm{mg} / \mathrm{kg} /$ day; Qi group: Daily fed by the Qi herbs $7 \mathrm{~g} / \mathrm{kg} /$ day; Blood group: Daily fed by the blood herbs $7 \mathrm{~g} / \mathrm{kg} /$ day; 1:2 group: Daily fed by formulated as prescribed proportion $21 \mathrm{~g} / \mathrm{kg} /$ day; 2:1 group: Daily fed by formulated as prescribed proportion $21 \mathrm{~g} / \mathrm{kg}$ g/day.

\section{Determined indexes}

After modeling, medicine intervention began within 24 hours, these animals were killed at 1 th, 2 th and 4 th week and then indexes were detected. Microvascular vascular count and the expression of vascular endothelial growth factor and endostatin protein were detected by immunohistochemistry and indexes were detected at 7th, 14th and 28th day according to the survival numbers in each group.

\section{Statistical analysis}

All data were presented as mean \pm S.D. Statistical analysis was performed with Excel 2003 and SPSS 17.0 for Windows. For comparison among multiple groups, data was analyzed by ANOVA. When a statistical difference appeared, the least significant difference (LSD) procedure or SNK was applied. A value of $\mathrm{p}<$ 0.05 was considered statistically significant. 


\section{Results}

\section{Observation under light microscope}

CD34 antibody staining status was observed under light microscope, and there were visible new capillaries in all groups. The sham group is not obvious, the model group had a small amount of blood capillary proliferation, the qi group and blood group had more proliferating capillaries and the musk group, 2:1 group and 1:2 group had most hyperplasia capillary.

\section{Microscopic view of cardiac muscle after HE staining}

The sham group: Myocardial structure is clear; the myocardial cells were in alignment, compacted connection, and there was no myocardial cell hypertrophy phenomenon; no inflammatory cell infiltration (Figure 1).

The model group: Myocardial cell in infarction area disappeared, instead by fibrous tissue; Fibrous tissue hyperplasia appeared on infarction boundary region, and few myocardial cells were remaining, which swelling, coagulation necrosis, with karyolysis disappearing, and muscle fibril fused into homogeneous red content. There were a large number of inflammatory cell infiltrations. Myocardial cell hypertrophy appeared on the infarction area, with arrangement disorder and inflammatory cells infiltration.

The qi group and blood group: Myocardial cell in infarction area disappeared, instead by fibrous tissue; Fibrous tissue hyperplasia appeared on infarction boundary region, and few myocardial cells were remaining, which swelling, coagulation necrosis, with karyolysis disappearing. There were a large number of inflammatory cell infiltrations. Myocardial cell hypertrophy appeared on the infarction area, with arrangement disorder and inflammatory cells infiltration. The entire symptom was better than the model group.
1:2 group, TXL group and 2:1 group: Myocardial cell in infarction area disappeared, instead by fibrous tissue; Fibrous tissue hyperplasia appeared on infarction boundary region, and few myocardial cells were remaining, which swelling, coagulation necrosis, with karyolysis disappearing. There were a large number of inflammatory cell infiltrations. Myocardial cell hypertrophy appeared on the infarction area, with arrangement disorder and inflammatory cells infiltration. The entire symptom was better than the qi group and blood group. 28 days: General form was observed under HE staining light microscope

\section{Comparison of microvascular vascular count expre- ssion}

Results showed that there was no difference in microvascular vascular count expression in the sham group. Compared with sham group, the microvascular vascular count expression of all group was significantly higher $(\mathrm{p}<0.05, \mathrm{p}<0.01)$ and the 1:2 Group, 2:1 group and TXL group were significantly highest. Compared with model group, the microvascular vascular count expression of 1:2 Group, 2:1 group and TXL group were significantly higher and the 2:1 group was the highest $(\mathrm{p}<0.01)$. The microvascular vascular count of model group was highest at 7 th day, which reduced over the time, and it was the same to the sham group at 28th day $(\mathrm{p}>0.05)$ (Table I). The microvascular vascular count increased with time and 1: 2 group, TXL group and 2: 1 group were significantly higher at 14 th day than at 7 th day $(\mathrm{p}<0.05)$, and 2: 1 group were significantly higher at 28 th day than at 14 th day $(p<0.05)$. There were statistical significances between TXL group and 2:1 group at 14 th and 28 th day. $(\mathrm{p}<0.05)$. Compared with model group, the microvascular vascular count expression of qi group and blood group were higher, however, there was no statistical significance between

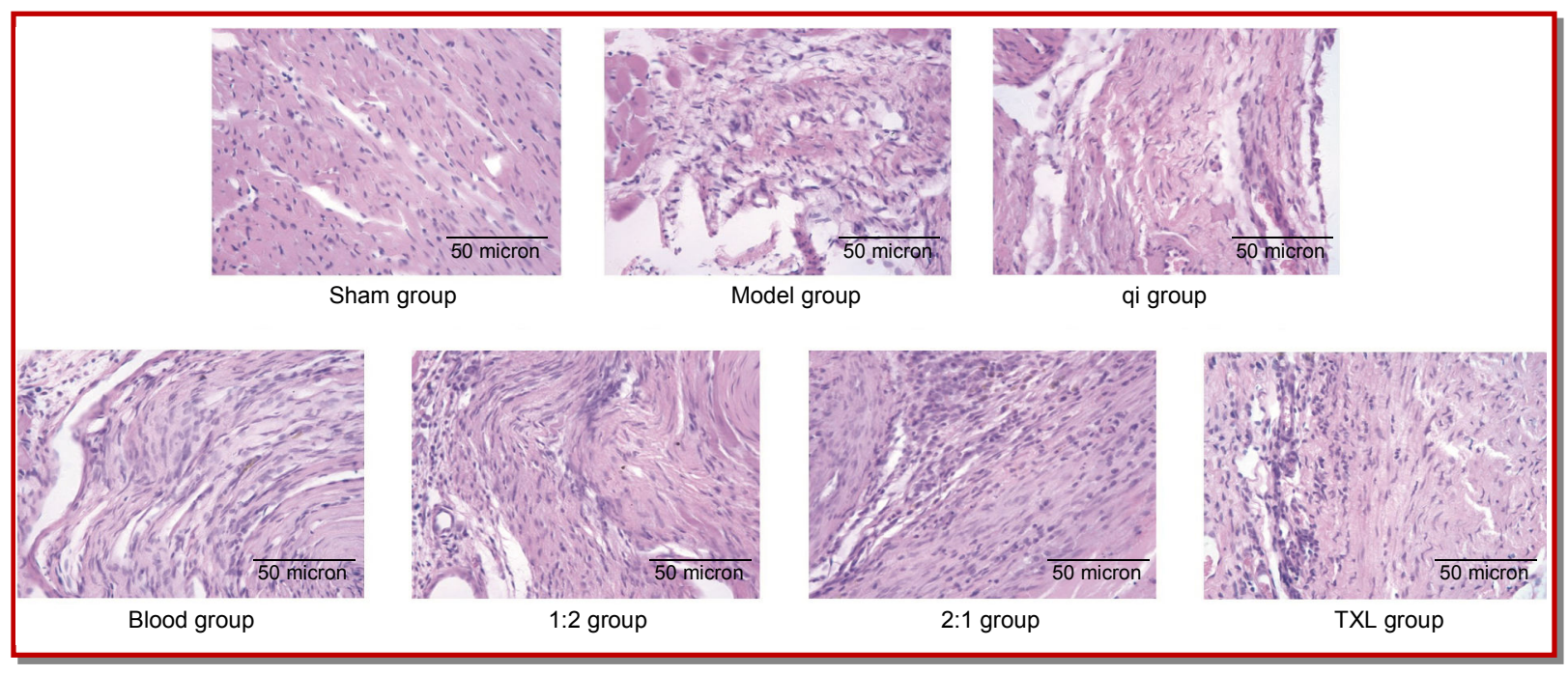

Figure 1: Microscopic view of cardiac muscle after HE staining in different groups 
Table I

Comparison of microvascular vascular count expression

\begin{tabular}{|lccc|}
\hline Group & Time & Time & Time \\
\hline Group & Day 7 & Day 14 & Day 28 \\
Sham group & $11.5 \pm 3.5$ & $11.6 \pm 4.0$ & $11.7 \pm 3.6$ \\
Model group & $17.3 \pm 3.2^{\mathrm{a}}$ & $15.37 \pm 3.7$ & $12.70 \pm 2.9^{\mathrm{a}}$ \\
Blood group & $20.0 \pm 3.4^{\mathrm{a}}$ & $26.1 \pm 3.9 \mathrm{ac}$ & $29.8 \pm 4.5^{\mathrm{bcd}}$ \\
Qi group & $20.4 \pm 3.4^{\mathrm{a}}$ & $27.4 \pm 4.8^{\mathrm{ac}}$ & $30.1 \pm 5.1^{\mathrm{bcd}}$ \\
$1:$ 2 group & $30.2 \pm 4.2^{\mathrm{bc}}$ & $41.9 \pm 4.5^{\mathrm{bcd}}$ & $46.3 \pm 6.3^{\mathrm{bcd}}$ \\
$2:$ group & $37.8 \pm 5.8^{\mathrm{bc}}$ & $51.8 \pm 6.3^{\mathrm{bcdf}}$ & $59.6 \pm 5.9^{\mathrm{bcef}}$ \\
TXL group & $31.7 \pm 4.8^{\mathrm{bc}}$ & $43.0 \pm 5.7 \mathrm{bcd}$ & $47.5 \pm 6.8^{\mathrm{bcd}}$ \\
\hline
\end{tabular}

Data are mean $\pm \mathrm{SD} ; \mathrm{n}=11$; One-way analysis of variance, compared with the sham group at the same time, ap $<0.05 \mathrm{~b} p<0.01$; compared with the model group at the same time, $c p<0.05$; compared with the same group at 1 th week, ${ }^{d} p<0.05 ; \quad$ compared with the same group at 2 th week, ep $<0.0$; compared with the TXL group at the same time, ${ }^{\mathrm{f}} \mathrm{p}<0.05$.

these two groups $(\mathrm{p}>0.05)$.

Comparison of vascular endothelial growth factor expression

Results showed that there was no difference in the sham group at different times (Table II). Compared with sham group, the vascular endothelial growth factor expression of the model group, qi group, blood group, 1:2 group, 2:1 group and TXL group was significantly high $(\mathrm{p}<0.01)$; Compared with the model group, the vascular endothelial growth factor expression of qi group, blood group, 1:2 group, 2:1 group and TXL group was significantly higher $(p<0.05)$. The vascular endothelial growth factor expression of model group was high at first week, which reduced with time, and was higher than the sham group at the same time $(\mathrm{p}<0.01 ; \mathrm{p}<0.05)$; The vascular endothelial growth factor expression of qi group, blood group, 1:2 group, 2:1 group and TXL group was significantly higher at second week than the first week $(p<0.05)$, however, there were statistical significances between the 4th week and 2nd week, which was higher than sham group and model group at the same time $(p<0.05)$. There was no statistical significance between TXL group and 1:2 group at the same time $(p>0.05)$. There was no statistical significance between qi group and blood group at the same time $(p>0.05)$. The VEGF expression of 2:1 group was significantly higher other groups $(\mathrm{p}<0.05)$, which compared with the TXL group, there was statistical significance $(\mathrm{p}<0.05)$ (Figure 2$)$.

\section{Comparison of endostatin protein expression}

Results showed that there was no difference in the sham group at different time $(p>0.05)$ (Table III). The endostatin protein expression of model group was high at first week, which reduced with time, and was same with the sham group at the same time $(p>0.05)$. The

Table II

Comparison of vascular endothelial growth factor expression

\begin{tabular}{lccc}
\hline Group & \multicolumn{3}{c}{ Time } \\
\cline { 2 - 4 } & Day 7 & Day 14 & Day 28 \\
Sham group & $11.8 \pm 0.9$ & $11.7 \pm 1.0$ & $11.8 \pm 0.9$ \\
Model group & $21.7 \pm 1.2^{\mathrm{b}}$ & $19.5 \pm 1.1^{\mathrm{bd}}$ & $12.8 \pm 0.8^{\mathrm{ade}}$ \\
Blood group & $24.7 \pm 1.4^{\mathrm{bc}}$ & $26.8 \pm 1.3^{\mathrm{bcd}}$ & $20.3 \pm 1.4^{\mathrm{bcde}}$ \\
Qi group & $23.7 \pm 1.3^{\mathrm{bc}}$ & $26.9 \pm 1.8^{\mathrm{bcd}}$ & $20.4 \pm 1.4^{\mathrm{bcde}}$ \\
$1:$ 2 group & $24.6 \pm 1.2^{\mathrm{bc}}$ & $28.7 \pm 1.3^{\mathrm{bcd}}$ & $23.6 \pm 1.3^{\mathrm{bce}}$ \\
$2:$ group & $27.6 \pm 1.5^{\mathrm{bcf}}$ & $32.7 \pm 2.1^{\mathrm{bcfd}}$ & $28.6 \pm 1.7^{\mathrm{bcfe}}$ \\
TXL group & $24.7 \pm 1.3^{\mathrm{bc}}$ & $29.0 \pm 1.6^{\mathrm{bcd}}$ & $23.8 \pm 1.4^{\mathrm{bce}}$ \\
\hline
\end{tabular}

Data are mean $\pm \mathrm{SD} ; \mathrm{n}=11$; One-way analysis of variance, compared with the sham group at the same time, a $\mathrm{p}<0.05$, ${ }^{\mathrm{b}} \mathrm{p}<0.01$; compared with the model group at the same time, ${ }^{c} \mathrm{p}<0.05$; compared with the same group at 1 th week, ${ }^{\mathrm{d}} \mathrm{p}<0.05$; compared with the same group at 2 th week, e $\mathrm{p}<0.0$; compared with the TXL group at the same time, $\mathrm{f}_{\mathrm{p}}<0.05$ 


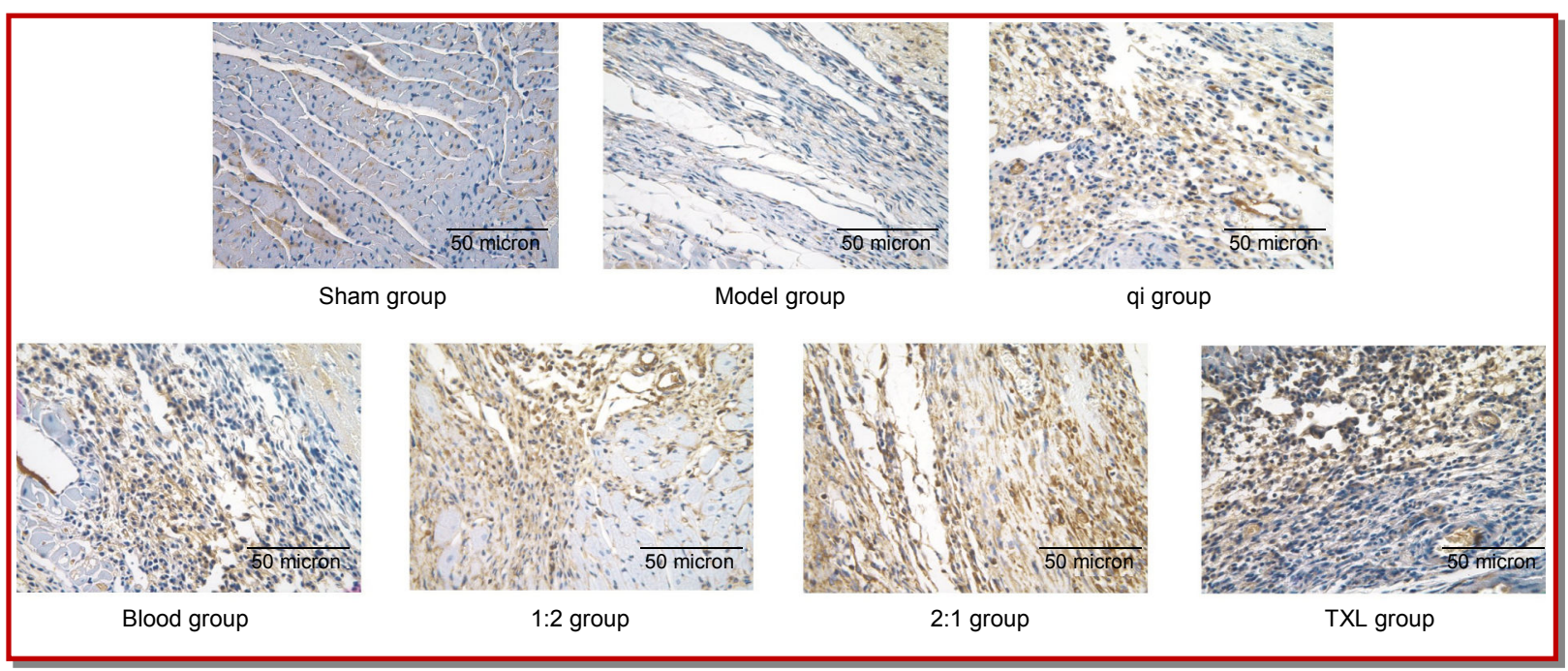

Figure 2: Vascular endothelial growth factor expression at day 28

\begin{tabular}{|c|c|c|c|}
\hline \multicolumn{4}{|c|}{ Table III } \\
\hline \multicolumn{4}{|c|}{ Comparison of endostatin protein expression } \\
\hline \multirow[t]{2}{*}{ Group } & \multicolumn{3}{|c|}{ Time } \\
\hline & Day 7 & Day 14 & Day 28 \\
\hline Sham group & $12.0 \pm 1.3$ & $11.9 \pm 1.4$ & $12.0 \pm 1.1$ \\
\hline Model group & $21.9 \pm 1.4^{\mathrm{a}}$ & $19.5 \pm 1.3^{\mathrm{ac}}$ & $11.8 \pm 1.1^{\mathrm{cd}}$ \\
\hline Blood group & $20.2 \pm 1.5^{\mathrm{ab}}$ & $22.6 \pm 17.9 \mathrm{abc}$ & $17.6 \pm 1.4^{\mathrm{abcd}}$ \\
\hline Qi group & $19.9 \pm 1.2^{\mathrm{ab}}$ & $22.5 \pm 2.0 \mathrm{abc}$ & $17.6 \pm 1.5^{\mathrm{abcd}}$ \\
\hline $1: 2$ group & $17.7 \pm 1.4^{\mathrm{ab}}$ & $19.0 \pm 1.2 \mathrm{ac}$ & $12.1 \pm 1.1^{\mathrm{cd}}$ \\
\hline $2: 1$ group & $15.6 \pm 0.7 \mathrm{aeb}$ & $16.7 \pm 0.7$ abec & $11.8 \pm 1.0^{\mathrm{cd}}$ \\
\hline TXL group & $17.6 \pm 1.3^{\mathrm{ab}}$ & $18.9 \pm 1.5^{\mathrm{ac}}$ & $12.3 \pm 1.3^{\mathrm{cd}}$ \\
\hline
\end{tabular}

Data are mean $\pm \mathrm{SD} ; \mathrm{n}=11$; One-way analysis of variance, compared with the sham group at the same time, ap $<0.05$; compared with the model group at the same time, ${ }^{b} \mathrm{p}<0.05$; compared with the same group at 1 th week, $\mathrm{c} p<0.05$; compared with the same group at 2 th $w e e k$, $\mathrm{d} p<0.0$; compared with the TXL group at the same time, ${ }^{\mathrm{e}} \mathrm{p}<0.05$

endostatin protein expression of qi group, blood group, 1:2 group, 2:1 group and TXL group was significantly higher at second week than the first week $(p>0.05)$, however, there were statistical significances between the 4th week and 2nd week, which was higher than sham group and model group at the same time $(p<0.05)$. The endostatin protein expression of qi group and blood group was higher than the sham group and lower than the model group at the same time at 1 th week $(p>0.05)$, and higher than the sham group and the model group at the same time at 2 nd and 4 th week $(\mathrm{p}<0.05)$, and there was statistical significance between these two groups $(p>0.05)$; The endostatin protein expression of 1:2 group and TXL group was higher than the sham group and lower than the model group at the same time at 1st week ( $>>0.05)$, higher than the sham group ( $p>0.05)$, same with the model group at the same time $(p>0.05)$, and the same with the sham group and model group at 4 th week $(p>0.05)$; The endostatin protein expression of 2:1 group was significantly lower than the model group ( $p>0.05)$, higher than the sham group at the same time at 1 st week $(p>0.05)$, lower than the TXL group $(p>0.05)$, significantly lower than the model group at the same time $(p>0.05)$, significantly higher than the sham group at the same time $(p<0.05)$, and there was statistical significance among the model group, sham group and the control groups $(\mathrm{p}>0.05)$ (Figure 3).

\section{Discussion}

The research showed that supplementing qi in combination with activating blood circulation herbs was better than pure application of supplementing qi and activating blood herbs in promoting angiogenesis through probably increased expression of vascular endothelial growth factor. Large doses of qi herbs combined with small doses of activating herbs are 


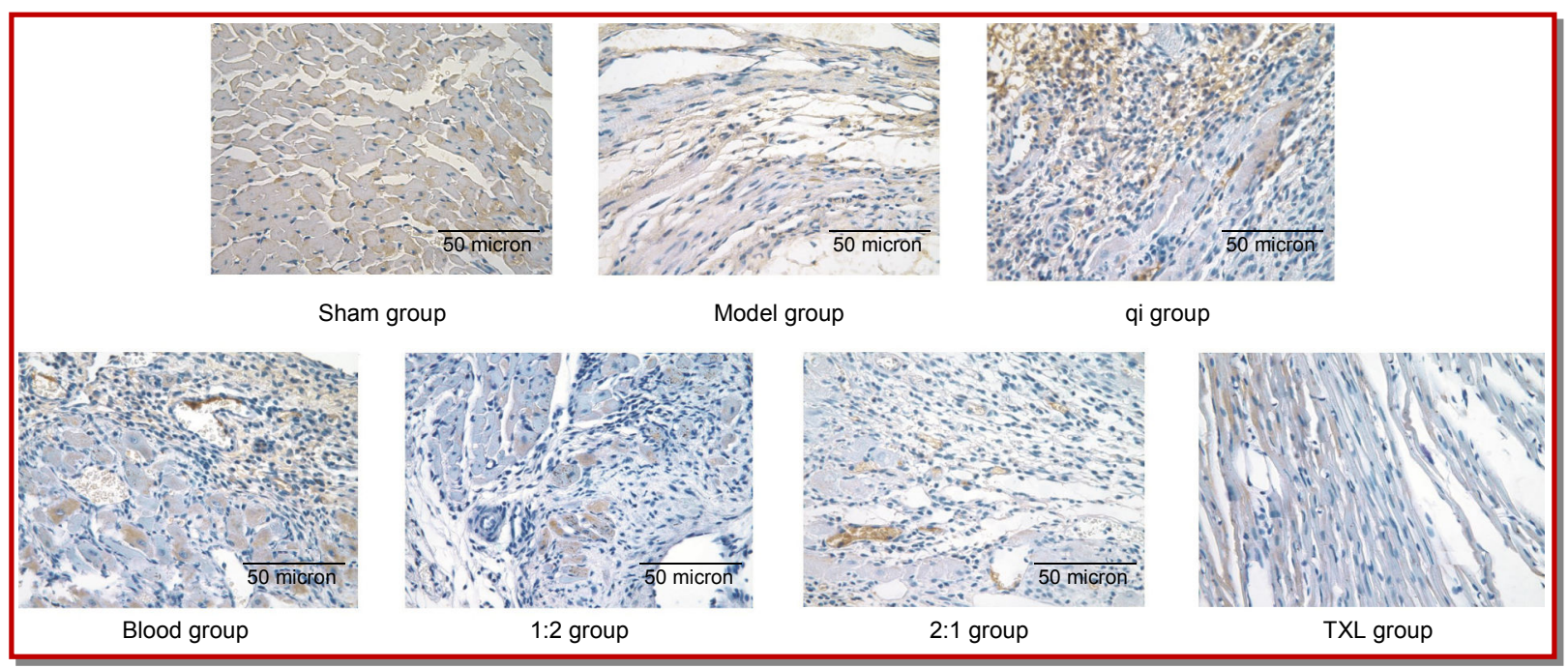

Figure 3: Endostatin protein expression at day 28

superior to small doses of supplementing qi and large doses of activating blood herbs in promoting the angiogenesis, increasing vascular endothelial growth factor protein expressions and reducing endostatin protein expressions. It showed that there was a doseresponse effect of supplementing $\mathrm{qi}$ and activating blood circulation herbs promoting angiogenesis. Time played an important role in this process. The mechanism of supplementing qi and activating blood circulation herbs and combination of both promoted angiogenesis due to possibly to increased vascular endothelial growth factor protein expressions and reduced endostatin protein expressions. Therefore, it seems that qi in combination with herbs that promote blood circulation could be beneficial possibly in patients with acute myocardial infarction.

Researchs showed that vascular endothelial growth factor isoforms and VEGFR subtypes are differentially expressed in the infarcted heart and increased VEGF-A in early stage of MI which suggests the potential role in initiating the cardiac angiogenic response (Zhao et al., 2013). Neutralization of endostatin protein worsens the symptoms and outcomes of myocardial infarction rats (Isobe et al., 2010). Gao et al. (2009) also showed that radix et Rhizoma Rhodiolae Kirilowii may promote angiogenesis in myocardium of rats with acute myocardial infarction through elevating the HIF-1alpha, HIF1 beta, and vascular endothelial growth factor expressions. Salidroside may be one of the effective components in Radix et Rhizoma Rhodiolae Kirilowii, which increases the expressions of HIF-1alpha, HIF-1beta and vascular endothelial growth factor during ischemia. Radix Ginseng and Radix Notoginseng extract can upregulate the protein and mRNA expressions of VEGFR2 and HIF-1 to improve myocardial ischemia so as to promote the development of collateral circulation (Du et al., 2010). Yu et al. (2015) showed that it is hypo- thesized that increased vascular endothelial growth factor and bFGF levels may contribute to the ASTinduced increase in angiogenesis in rat models of myocardial infarction. In our research, we showed that there was a dose-response effect of supplementing qi and activating blood circulation herbs promoting angiogenesis. Spplementing qi in combination with activating blood circulation herbs was better than other groups and qi deficiency is the basic pathogenesis of myocardial infarction.

Although the research explained part of reason of treatment of acute myocardial infarction rats by supplementing qi in combination with activating blood circulation herbs, there are more mechanism such as inflammation, immunology its need to be further mining and further studies may be necessary to validate these findings in experimental animals to human patients.

\section{Conclusion}

The study indicated the beneficial effects of qi and its combination to promote angiogenesis and increase blood flow to the tissue surrounding the infarcted one. Furthermore, supplementing qi and activating blood circulation herbs and its proper combination can promote greater oxygenation and blood perfusion through angiogenesis and blood circulation.

\section{Ethical Issue}

The animal experiments were performed in accordance with the standards established by the Guide for the Care and Use of Laboratory Animals of Beijing City, and approved by the local ethics committee. The whole lab process was carried out under the permission and surveillance of the ethical committee. 


\section{Conflict of Interest}

We declare that we have no conflict of interest.

\section{Acknowledgement}

This research was supported by the National Natural Science Foundation of China (81173142 and 81473552), and Talents Training and Supporting Project at Dongcheng District (Hold by Chenglong Zheng).

\section{References}

Du XJ, Lei Y,Yang J. Effects of Radix Ginseng and Radix Notoginseng formula on expressions of vascular endothelial growth factor receptor-2 and hypoxia-inducible factor-1 alpha in ischemic myocardium of rats with acute myocardial infarction. Zhong Xi Yi Jie He Xue Bao. 2010; 8: 548-53.

Gao XF, Shi HM, Sun T, Ao H. Effects of Radix et Rhizoma Rhodiolae Kirilowii on expressions of von Willebrand factor, hypoxia-inducible factor1 and vascular endothelial growth factor in myocardium of rats with acute myocardial infarction. Zhong Xi Yi Jie He Xue Bao. 2009; 7: 434-40.

Guo SW, Cui W, Wang SR, Niu FL, Wang GH. Time-phase changed character of cardiac muscle cell apoptosis and proliferation induced by angiotensin II and influences of TCM herbs for supplementing Qi and activating blood circulation on it. JITWM. 2005; 25: 1004-07.

Guo SW, Wang GH, Qin LM, Niu FL, Wang SR, Lu JQ, Liu ZQ, Yan YF. Effects of some Chinese herbs on changes of energy and lipid peroxidation in cardiac cells induced by Angiotensin II. J Beijing Univ Traditional Chinese Med. 2005; 28: 32-35.

Guo SW, Zheng CL, Huang PP, Zhang L, Yang PC, Zhang JF, Zhou JY, Huang K, Yang DD, Sun Q. Effects of supplementing qi and activating blood circulation herbs on expressions of basic fibroblast growth factor and platelet endothelial cell adhesion molecule-1 in ischemic myocardium of rats with acute myocardial infarction. Afr J
Pharm Pharmacol. 2012; 6: 2735-41.

Halkos ME, Rab ST, Vassiliades TA, Morris DC, Douglas JS, Kilgo PD, Liberman HA, Guyton RA, Thourani VH, Puskas JD. Hybrid coronary revascularization versus off-pump coronary artery bypass for the treatment of left main coronary stenosis. Ann Thorac Surg. 2011; 92: 2155-60.

Isobe KI, Kuba K, Maejima Y, Suzuki J, Kubota S, Isobe M. Inhibition of endostatin/collagen XVIII deteriorates left ventricular remodeling and heart failure in rat myocardial infarction model. Circ J. 2010; 74: 109-19.

Jazi SM, Esfahani MH, Fesharaki M, Moulavi F, Gharipour M. Initial clinical outcomes of intracoronary infusion of autologous progenitor cells in patients with acute myocardial infarction. ARYA Atheroscler. 2012; 7: 162-67.

Jung S, Wermker K, Poetschik H, Ziebura T, Kleinheinz J.The impact of hyperbaric oxygen therapy on serological values of vascular endothelial growth factor (VEGF) and basic fibroblast growth factor (bFGF).Head Face Med. 2010; 6: 261 65.

Koyama H. Therapeutic angiogenesis for the treatment of ischemic heart disease. Nihon Rinsho. 2011; 69: 316-19.

Lee KH, Choi SI, Chun EJ, Kim JA, Lee MS, Yoon CH, Choi DJ. Aborted myocardial infarction: Evaluation of changes in area at risk, late gadolinium enhancement, and perfusion over time and comparison with overt myocardial infarction. Am J Roentgenol. 2012; 199: 328-35.

Stanton LW, Garrard LJ, Damm D, Garrick BL, Lam A, Kapoun AM, Zheng Q. Altered patterns of gene-expression in response to myocardial infarction. Circ. Res. 2000; 86: 93945.

Yu JM, Zhang XB, Jiang W, Wang HD, Zhang YN. Astragalosides promote angiogenesis via vascular endothelial growth factor and basic fibro-blast growth factor in a rat model of myocardial infarction. Mol Med Rep. 2015; 12: 6718 $-26$.

Zhao TQ, Zhao WY, Chen YG, Liu L, Ahokas RA, Sun Y. Differential expression of vascular endothelial growth factor isoforms and receptor subtypes in the infarcted heart. Int J Cardiol. 2013; 167: 2638-45. 


\section{Your feedback about this paper}

1. Number of times you have read this paper 0

2. Quality of paper
Excellent
O Good
Ooderate
Not good

3. Your comments 